\title{
Corrosion mechanisms in titanium oxide-based films produced by anodic treatment
}

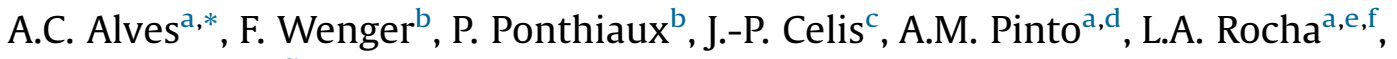 \\ J.C.S. Fernandes ${ }^{g}$ \\ a CMEMS-UMinho - Center of MicroElectroMechanical Systems - Universidade do Minho, Azurém, 4800-058 Guimarães, Portugal \\ ${ }^{\mathrm{b}}$ LGPM - Laboratoire de Génie des Procédés et Matériaux - École Centrale Paris, France \\ ${ }^{\mathrm{c}}$ MTM - Materials Engineering - KULeuven, Belgium \\ d Dep. Mechanical Engineering - University of Minho, Portugal \\ e Dep. Physics, Faculdade de Ciências de Bauru, UNESP - Universidade Estadual Paulista, Brazil \\ ${ }^{\mathrm{f}} \mathrm{IBTN} / \mathrm{Br}$ - Brazilian Branch of the Institute of Biomaterials, Tribocorrosion and Nanomedicine, Bauru, Brazil \\ ${ }^{g}$ CQE/DEQ - Instituto Superior Técnico, Universidade de Lisboa, Lisboa, Portugal
}

\section{A R T I C L E I N F O}

\section{Article history:}

Received 12 October 2016

Received in revised form 2 March 2017

Accepted 2 March 2017

Available online 4 March 2017

\section{Keywords:}

Titanium

Biomaterial

Anodic treatment

Corrosion

EIS

\section{A B S T R A C T}

Thanks to its excellent corrosion resistance, good mechanical properties and biocompatibility, titanium has been widely used as dental implant material. A passive oxide film formed on titanium surface is responsible for its high corrosion resistance. This study has evaluated the surface characteristics of oxide layers formed on commercially pure titanium samples by anodic treatment and the effect of anodic treatment on their corrosion behaviour. FEG-SEM and XRD were used to evaluate the micromorphology and crystalline structure of these oxide films. Their corrosion resistance was evaluated using electrochemical impedance spectroscopy (EIS) and potentiodynamic polarization curves. EIS was performed for different times of immersion and a new equivalent electrical circuit (EEC) is proposed to fit the experimental data of the anodic oxide films. It was concluded that the morphology, composition, and structure of the outer porous layer of the anodic layer determine the corrosion protection of the material. (C) 2017 Elsevier Ltd. All rights reserved.

\section{Introduction}

In comparison with other metallic biomaterials (Co-Cr alloys and stainless steels), titanium (Ti) possess the most adequate balance of characteristics for several biomedical applications, namely dental implants. High biocompatibility, specific strength, and corrosion resistance may be pointed out as the most interesting features for those applications [1-4]. However, being a bio-inert metal, titanium does not have the ability to chemically bond with the natural bone [5-8].

Although it was shown that metallic dental implants coated with hydroxyapatite (HA) display enhanced biological response compared to uncoated implants [9], lack of adhesion of HA coatings to the metallic substrate and/or fracture or delamination of the coating are liable to occur [10]. Thus, several surface modification techniques, as plasma-spraying [9,11,12], ion

\footnotetext{
* Corresponding author at: University of Minho - Department of Mechanical Engineering - Campus de Azurém, 4800-058 Guimarães, Portugal. Tel.: +351253510 220; fax: +351253516007.

E-mail address: alexandra@dem.uminho.pt (A.C. Alves).
}

implantation [13-15], sol-gel deposition [16,17] and anodic treatment $[10,18-24]$ have been investigated in order to produce surface layers with improved bioactivity. Due to their simplicity, anodic treatments appear as attractive techniques for tailoring $\mathrm{Ti}$ surfaces in terms of topography, porosity, and composition [19,2128].

In the 90's, Ishizawa and Ogino [10,19-21,29,30] were among the first authors to perform surface modification of $\mathrm{Ti}$ with the incorporation of bio-elements such as $\mathrm{Ca}$ and P. An electrolyte consisting of calcium acetate and $\beta$-glycerophosphate disodium salt pentahydrate was used to form anodic titanium oxide films containing $\mathrm{Ca}$ and $\mathrm{P}$ in different amounts depending on the processing conditions. The authors observed precipitation of HA crystals after a hydrothermal treatment [10,19,20,29,30].

Several authors have characterized different porous anodic oxide films formed by micro-arc oxidation (MAO) on Ti or its alloys, in terms of crystalline structure, topography, porosity, composition, corrosion behaviour and biological response [710,19,21,22,24,26-48]. Electrochemical impedance spectroscopy (EIS) was also used by several authors to characterize those films $[24,31,33,34,49,50]$. Nevertheless, discussion on the most suitable 
equivalent electrical circuits (EEC) for interpreting EIS results is still going on. Most of the authors assume that the anodic oxide film is composed of two-layers, an inner barrier layer followed by a porous outer layer, thus adopting the equivalent circuit proposed by Pan et. al [51] for two-layers oxide film on anodised Ti.

An acceptable equivalent circuit should meet two main conditions: first of all it should provide a good fitting to the EIS experimental data and secondly it should have a clear and valid physical meaning. In particular, a clear description of the different paths for the flow of current should be done, allowing to distinguish between electronic and ionic charge carriers and between the faradaic and non-faradaic paths, as proposed by Grahame [52]. As the number of time constants present in the data increases, the number of degenerate EEC's that fit the data also increases, but most of them have no physical meaning.

Some of the present authors had previously reported [45] that increased concentration of calcium acetate in the mixture of $\beta$-glycerophosphate and calcium acetate anodic treatment electrolyte led to better tribocorrosion behaviour, due to the alteration of the crystallographic structure of the resulting anodic layer. The present work aims to study, for the first time, the electrochemical properties of Ti anodic oxide layers during long-time immersion in a physiological solution using EIS. In particular, a new EEC to fit the experimental data is proposed, based on a detailed characterization of the anodic layers.

\section{Experimental}

\subsection{Materials and solutions}

Commercial pure titanium (CP Ti grade 2, Goodfellow Cambridge Limited, England) samples were cut from the same original plate in square forms of $10 \times 10 \times 1 \mathrm{~mm}$. Immediately before the anodic treatment all the samples were cleaned in an ultrasonic bath with acetone for $3 \mathrm{~min}$, etched in Kroll's reagent ( $1 \mathrm{ml} \mathrm{HF}$ and $5 \mathrm{ml} \mathrm{HNO}_{3}$ in $44 \mathrm{ml} \mathrm{H}_{2} \mathrm{O}$ ) during $10 \mathrm{~min}$, and cleaned again in an ultrasonic bath for $10 \mathrm{~min}$ in propanol followed by $5 \mathrm{~min}$ rinsing in distilled water, and then dried with warm air.

The electrolyte used for the anodic treatment consisted in a solution of $\beta$-glycerophosphate disodium salt pentahydrate $(\beta-G P)$ at different concentrations of calcium acetate monohydrate (CA) as depicted in Table 1. After the anodic treatment, electrochemical tests were performed in an $8 \mathrm{~g} / \mathrm{l} \mathrm{NaCl}$ solution. The reagents used in the preparation of these solutions were supplied by Fluka-BioChemika, Sigma-Aldrich and Panreac, respectively.

\subsection{Anodic treatment}

The anodic treatment was performed under constant voltage mode. A DC power supply (GPR-30H10D) was used and the treatment was carried out at room temperature for $1 \mathrm{~min}$ at $300 \mathrm{~V}$, under a sparking regime. A platinum plate was used as cathode $\left(2 \mathrm{~cm}^{2}\right)$. The distance between the cathode and the anode ( $\mathrm{Ti}$ plates) was kept constant $(8 \mathrm{~cm})$ for each treatment. The surface area of the titanium samples exposed to the electrolyte solution was $0.358 \mathrm{~cm}^{2}$. All the anodic treatments were done under

\section{Table 1}

Samples under study and electrolyte composition.

\begin{tabular}{ll}
\hline Group & Electrolyte \\
\hline 015 CA & $0.02 \mathrm{~mol} / 1 \beta-G P+0.15 \mathrm{~mol} / \mathrm{l} \mathrm{CA}$ \\
035 CA & $0.02 \mathrm{~mol} / 1 \beta-G P+0.35 \mathrm{~mol} / 1 \mathrm{CA}$ \\
CP Ti & just etched \\
\hline
\end{tabular}

agitation in a turbulent regime by using a magnetic stirrer rotating at $200 \mathrm{rpm}$.

\subsection{Electrochemical tests}

Electrochemical tests consisted of open circuit potential $\left(\mathrm{E}_{\mathrm{ocp}}\right)$ measurements, potentiodynamic polarization curves, and electrochemical impedance spectroscopy (EIS). All the electrochemical tests were performed using a 3-electrode arrangement where the samples were used as working electrode, with an exposed area of $0.358 \mathrm{~cm}^{2}$, a Pt electrode was used as counter electrode and a saturated calomel electrode (SCE) was used as reference electrode. All the potentials are given with respect to SCE.

All electrochemical tests were performed using a Reference 600 potentiostat/galvanostat from Gamry Instruments. The potential scan rate in the potentiodynamic tests was $1 \mathrm{mV} / \mathrm{s}$, starting at $0.5 \mathrm{~V}$ below $\mathrm{E}_{\text {ocp }}$ and moving into the anodic direction up to $2 \mathrm{~V}$.

The EIS tests were done for different times of immersion in the test solution ( 0 h, 1 h, 1 day, 2 days, 4 days, 8 days, 16 days, and 20 days) at $\mathrm{E}_{\text {ocp }}$. Before each EIS test the $\mathrm{E}_{\text {ocp }}$ was measured during $30 \mathrm{~min}$. The impedance data acquisition was done by scanning a range of frequencies from $63 \mathrm{kHz}$ till $10 \mathrm{mHz}$, with 10 points per frequency decade, and the amplitude of the sinusoidal signal was $10 \mathrm{mV}$, in order to guarantee linearity of the electrode response.

\subsection{Characterization Methods}

The topography, microstructure and chemical composition of the anodic oxide layers formed on the surface were analysed by scanning electron microscope, FEI Nova 200 Field Emission Gun Scanning Electron Microscope (FEG-SEM) equipped with Energy Dispersive X-Ray Spectroscopy (EDS). The cross sections of the anodic oxide films were prepared by nano-machining using the focused ion beam of a SEM-FIB (Nova 600 NanoLab) and characterized by FEG-SEM/EDS.

The surface roughness was measured on five randomly selected samples (using five different areas on each sample), using a high resolution optical sensor from STIL (model CHR150-N), a 3D motion measuring station, a controlling system from STIL and an optic sensor (F3) from ZEISS.

The structure of the anodic layers was analysed by X-ray diffraction with Bragg-Brentano, Göbel mirror mode, $\mathrm{CuK} \alpha$ radiation (Bruker D8 Discover). A scanning range $(2 \theta)$ of $10^{\circ}$ to $100^{\circ}$ was used, and the step size was set to $0.02^{\circ}$. The peaks identification was done using Diffrac Plus Evaluation (Package Release 2006) software. The phase percentage (distribution) was calculated following Eq. (1).

$\%$ phase $\alpha_{\alpha}=\frac{\sum I_{\alpha \text { peaks }}}{\sum I_{\text {all peaks }}}$

\section{Results and Discussion}

\subsection{Characterization of the anodic films}

\subsubsection{Surface morphology}

Fig. 1 presents the current density evolution during the formation of the anodic oxide layers at $300 \mathrm{~V}$ in the two different electrolytes. After an initial current peak, a decrease is observed in the early stages of the anodic treatment, being attributed to the formation of a compact and thin oxide layer [37-39,42,53].When the thickness of the oxide films reach a critical value, the applied voltage promotes the dielectric breakdown of these films and micro-arc discharge start to occur at the surface of the material, leading to localised melting and formation of micro-pores 


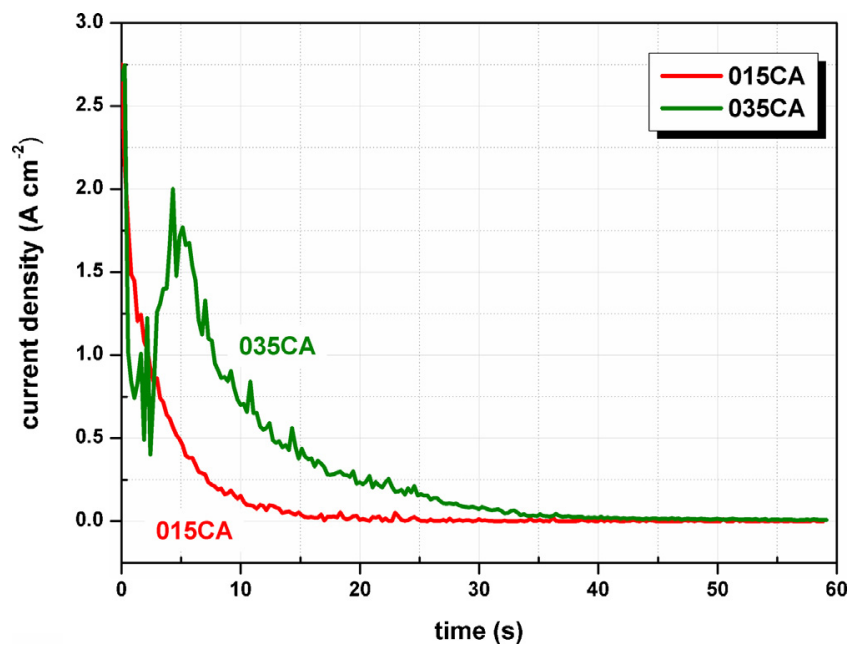

Fig. 1. Current densities evolution during the anodic treatment time at $300 \mathrm{~V}$ for two different electrolyte concentrations.

$[28,42,49]$. Micro-arc discharges are identified in the curves by the current oscillations during the treatment. These discharges accelerate the growth of the layer, which then leads to a decrease of the current density.

A representative SEM micrograph of the untreated Ti after etching (before the anodic treatment) is shown in Fig. 2 (a), where the typical granular structure of Ti can be observed. Fig. 2(b) and (c) show the surface morphology after anodic treatment in $0.15 \mathrm{M}$ and 0.35 M CA, respectively. As can be observed, a multiscale porous structure was obtained with some cracks being observed on the surface of both groups of samples. The arrows shown in Fig. 2 (c) identify some of the cracks present in the 035CA group. The density of cracks and distribution of pores size were calculated using a point-counting method adapted from ASTM E562. A grid consisting of a 15 lines parallel to each other with a constant spacing of $0.05 \mathrm{~mm}$ was superimposed on the micrograph. All the pores intersecting the lines were counted and their diameters were measured. Five SEM images were taken for each sample in different zones of the surface and five samples were used per condition. It could be observed that for 015CA group the crack density was of $(1.1 \pm 0.4) \times 10^{3}$ cracks $/ \mathrm{mm}^{2}$ while for 035CA it is higher, namely $(7.1 \pm 1.6) \times 10^{3} \mathrm{cracks} / \mathrm{mm}^{2}$. An increase of the number of cracks with the increase of the calcium acetate concentration was also observed by S-D Wu et al. [53].

Also, an increase in the amount of calcium acetate in the electrolytic solution resulted in higher pore diameters, as shown in Fig. 3. Finally, the anodic treatment resulted in pores with a wide range of sizes [28]. Regarding the 015CA group, most of the pores have a diameter between 0.5 and $1 \mu \mathrm{m}$, with a maximum size of $3.5 \mu \mathrm{m}$. In the 035CA group, the size of pores increased, and their diameter is between 1.5 and $2 \mu \mathrm{m}$, for most pores, with a maximum size of $5 \mu \mathrm{m}$.

Comparing the pores size dispersion of both groups, it was observed that the 035CA group presents a larger dispersion than 015CA. Also, the number of pores per surface area was different in both groups, namely $(34 \pm 3) \times 10^{3}$ pores $/ \mathrm{mm}^{2}$ for the $015 \mathrm{CA}$ and $(24 \pm 3) \times 10^{3}$ pores $/ \mathrm{mm}^{2}$ for the $035 \mathrm{CA}$. The increase on the pores size with increasing electrolyte concentration has also been reported by Ishizawa et al. [21] for anodic titanium oxide films containing $\mathrm{Ca}$ and $\mathrm{P}$, processed by similar anodic treatment conditions. The microstructural differences between the two anodized surfaces are attributed to the dielectric breakdown of the oxides layers [32]. The increase of calcium acetate concentration in the electrolyte may improve the electrical conductivity of
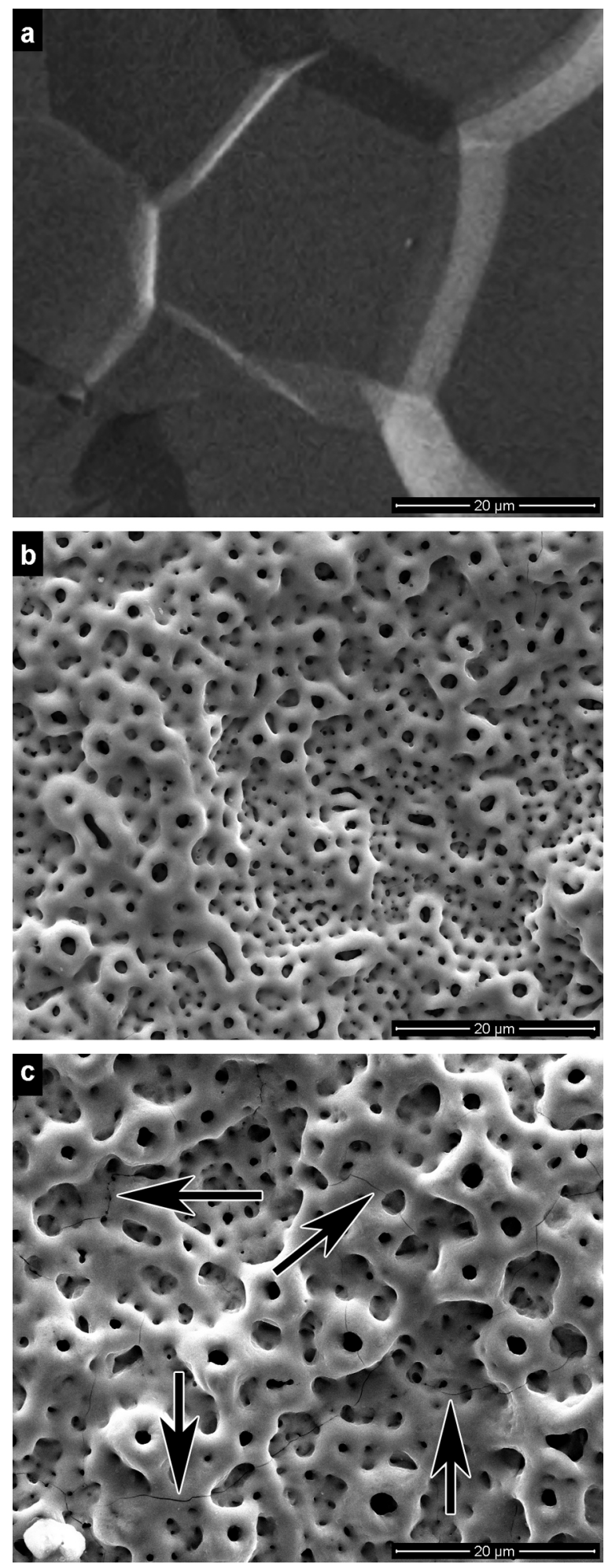

Fig. 2. Representative SE SEM images of the titanium samples for different surface conditions: a) etched, and anodic treated groups b) 015 CA and c) 035 CA.

the electrolyte. S. Abbasi et al. [37] stated that the variation in electrical resistance of the electrolyte is the main reason for the pore size enlargement at higher concentrations of calcium acetate.

In terms of roughness, the acid etched surface (just before anodic treatment) presented a mean roughness $\left(R_{a}\right)$ of $0.42 \pm 0.02 \mu \mathrm{m}$. After the anodic treatment the roughness 


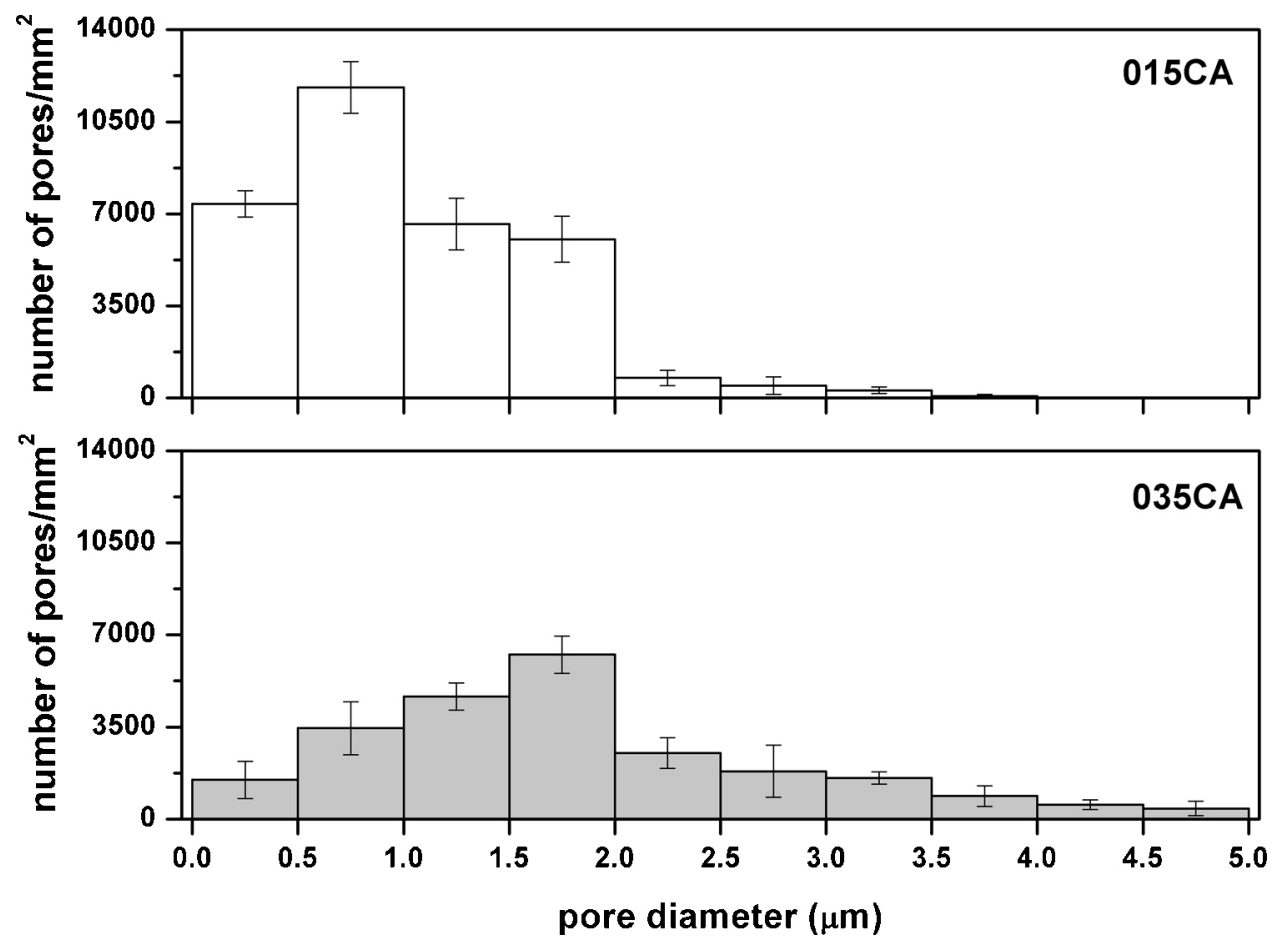

Fig. 3. Pore size distribution on the anodic treated surfaces for two different electrolyte concentrations.

increased around 4 times, up to $1.64 \pm 0.36 \mu \mathrm{m}$ and $1.66 \pm 0.22 \mu \mathrm{m}$ for group 015CA and 035CA, respectively.

\subsubsection{Anodic films composition and structure}

The $\mathrm{Ca} / \mathrm{P}$ weight ratio of the anodic films was estimated by EDS analysis, being strongly influenced by the calcium acetate concentration. The $\mathrm{Ca} / \mathrm{P}$ ratio for the 015CA group $(1.61 \pm 0.09)$ was lower than for 035CA $(3.62 \pm 0.11)$.

Under sparking conditions, local heating occurs and high temperatures can be reached, so water vapour and oxygen are released [18]. During this process, specific ions as Ca and P can be retained in the porous oxide layer $[19,20,22]$. This is one advantage of this anodic treatment, as the presence of these ions may improve osteointegration $[43,46,47]$.

The presence of HA is known as beneficial to the implants, as it promotes a direct bonding to the bone and enhancement of new bone formation around it. Many studies have proved that HA coated implants show superior histological results than the uncoated ones [30]. The Ca/P ratio on HA is 1.67 . In this way, it may be expected that by changing the concentration of the electrolyte of the anodic treatment, a $\mathrm{Ca} / \mathrm{P}$ ratio similar to the one in HA may be reached. Ishizawa et al. $[19,20,30]$ have shown that several HA crystals precipitated in the anodic titanium oxide layer containing $\mathrm{Ca}$ and $\mathrm{P}$ after a hydrothermal treatment, when the $\mathrm{Ca} / \mathrm{P}$ ratio was similar to HA.

Anyway, even without HA precipitation, samples investigated in this work showed enhanced human osteoblast adhesion when tested in vitro $[43,46,47]$.

The cross section of the anodic films is shown in Fig. 4a-d. Both anodic films presented three different layers. Adjacent to the bulk material (Ti) a compact film was formed (A) followed by two porous outer layers. The inner porous layer, marked in Fig. 4 as B, presented small pores, whereas the outer porous layer $(C)$ formed near the outer surface presented bigger pores.

The thickness of the anodic films was measured by image analysis. The 035CA group has a slightly increased thickness $(4.38 \pm 1.21 \mu \mathrm{m})$ compared to the 015CA group $(3.39 \pm 1.04 \mu \mathrm{m})$.
The X-ray patterns obtained for the anodic treated samples, as well as for untreated Ti, are shown in Fig. 5 (only the $2 \theta$ values from $20^{\circ}$ to $60^{\circ}$ are shown, as this is the range where the characteristics peaks for $\mathrm{Ti}$ and $\mathrm{Ti}$ oxides are found). Ti diffraction peaks were observed on all groups: 015CA presented anatase, and 035CA both anatase and rutile.

Kim et al. [25] have found that anodic treatment of titanium in a calcium glycerophosphate /calcium acetate electrolyte produced layers with two crystalline phases, as rutile and anatase. On the other hand, Sul et al. [54] have shown that the structure of the anodic layer is changed from amorphous to crystalline, meaning that formation of the anatase, rutile or brokite occurs above a critical oxide thickness. The electrochemical parameters, as electrolyte concentration or the current density, influence the dielectric breakdown potential, which is related to the crystallographic transformation. It has been reported that after the dielectric breakdown, anatase is formed at lower forming voltages, while the combination of anatase and rutile phases is formed at higher forming voltages $[36,55,56]$. However, the forming voltages of both phases may decrease when the conductivity of the electrolyte increases. In this case, by increasing the concentration of calcium acetate the dielectric breakdown changed and, probably due to this fact, the anodic oxide layer was formed as a combination of anatase and rutile phases on the 035CA group. Since no rutile was detected in the case of 015CA group, it is assumed that the crystalline phase of the anodic oxide layer was $100 \%$ anatase. The phase percentages (phase distribution) regarding 035CA group were calculated by Eq. (1), and the results showed that the anodic oxide layer was a combination of $70 \%$ anatase and $30 \%$ rutile.

\subsection{Electrochemical behaviour}

\subsubsection{Potentiodynamic Polarization curves}

Fig. 6 shows the polarization curves of the untreated titanium samples and anodic treated groups of samples. The average corrosion potential, $E_{(i=O)}$, and the average passive current density, 

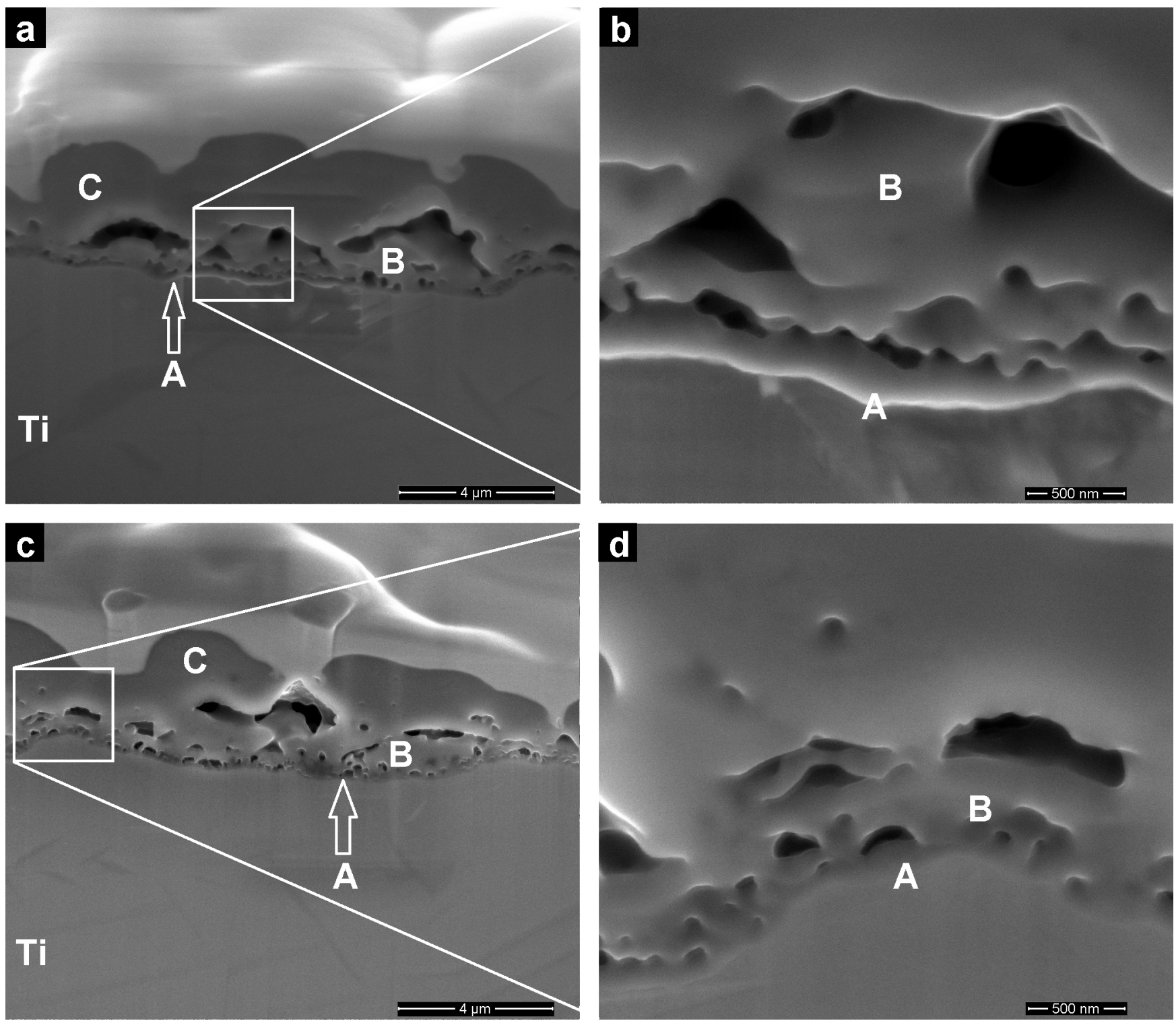

Fig. 4. SE SEM images of a FIB-prepared cross-sections of anodic layers for two different electrolyte concentrations: a) and b) $015 C A$ - c) and d) 035CA.

$i_{\text {pass }}$, obtained from several experiments (up to seven) in each group, are presented in Table 2.

The corrosion potential showed a clear increase from untreated Ti to the 015CA group, followed by a slight decrease from 015CA to 035CA. A passivation plateau was observed for all types of specimens, starting at $0.250 \mathrm{~V}$ for $\mathrm{Ti}$, whereas for 015CA it was registered from $0.191 \mathrm{~V}$ to $0.652 \mathrm{~V}$, being followed by a slight increase of the current that corresponds to a degradation of the protective film, possibly due to the dissolution of calcium and phosphorous. For the 035CA group, the passive domain is observed from 0.064 to $0.580 \mathrm{~V}$. The $\mathrm{i}_{\text {pass }}$ values showed a two orders of magnitude drop from $\mathrm{Ti}$ to $015 \mathrm{Ca}$, with a slight increase from 015CA to 035CA. Although the passive range seems to be reduced from the untreated $\mathrm{Ti}$ to both treated materials, even above this primary passive range and up to $2 \mathrm{~V}$ (the maximum applied potential) the values of current density are always much lower than those observed for Ti. Thus, both the $\mathrm{E}_{\mathrm{i}=0}$ and the $\mathrm{i}_{\text {pass }}$ values indicated an evident tendency for the improvement of the corrosion resistance on the MAO-processed materials, the 015CA group showing the best properties.
Il.S. Park et al. [28] have studied the corrosion resistance of CP Ti (grade 2) anodized in similar conditions. They have also reported higher corrosion potential value and lower current density as compared with untreated Ti. The authors attributed these results to the increased resistance of the oxide layer to corrosion through the anodic treatment. Previous studies $[8,28]$ also defended that, beyond the increase in roughness, which is desirable for many biomedical applications, the increase in thickness of the oxide layer obtained through MAO also results in an improvement of the corrosion resistance, compared to untreated $\mathrm{Ti}$.

\subsubsection{Open Circuit Potential evolution versus immersion time}

The evolution of OCP with immersion time for untreated and anodic treated Ti samples in $8 \mathrm{~g} / \mathrm{l}$ of $\mathrm{NaCl}$ is presented in Fig. 7. After exposing all samples to the solution, the OCP for the untreated $\mathrm{Ti}$ increased while it decreased for the anodic treated samples. For the untreated Ti samples, the increase on OCP values with immersion time corresponded to the decrease of the anodic reaction kinetics due to the formation of the natural oxide film of titanium in contact with the electrolyte $[41,57]$. Regarding the anodic treated samples, the decrease on OCP with immersion time may be related to partial 


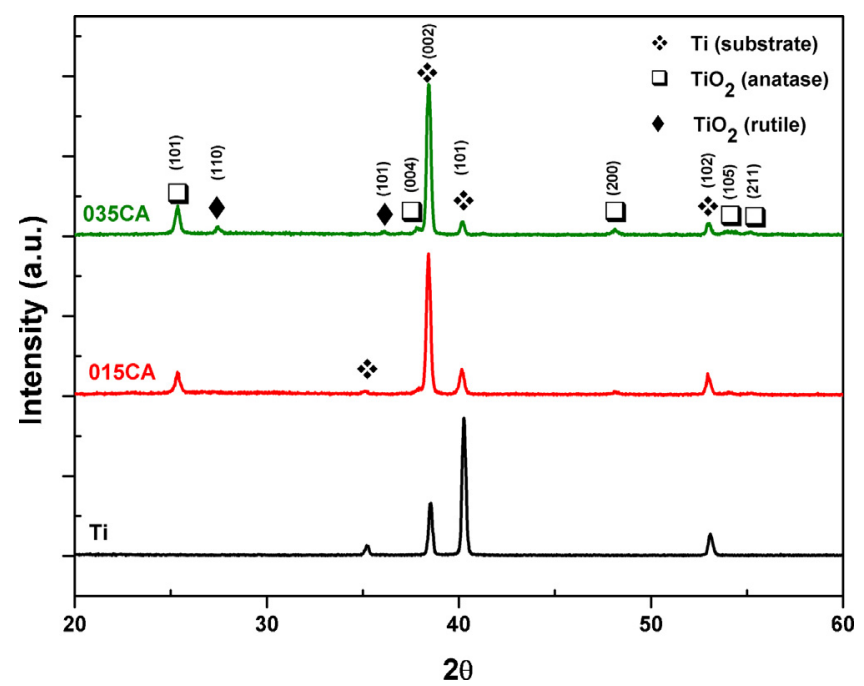

Fig. 5. X-ray diffraction patterns obtained for groups 015CA, 035CA, together with untreated Ti.

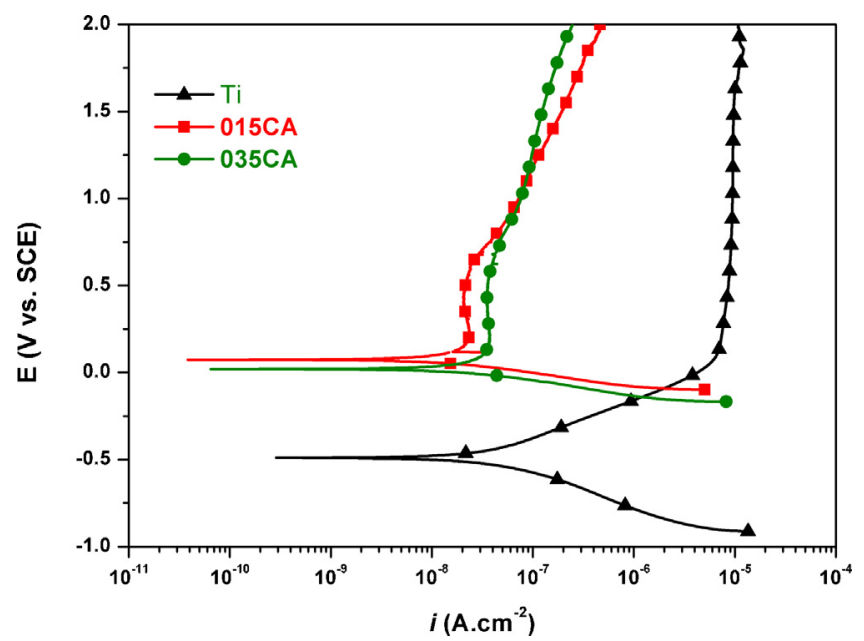

Fig. 6. Potentiodynamic polarization curves of the different groups of samples in $\mathrm{NaCl}(8 \mathrm{~g} / \mathrm{l})$.

Table 2

Average values of corrosion potential, $E_{(i=O)}$, and passivation current density, $i_{\text {pass, }}$ for all groups.

\begin{tabular}{lll}
\hline Group & $\mathrm{E}_{(\boldsymbol{i}=\boldsymbol{O})}(\mathrm{V}$ vs. SCE $)$ & $i_{\text {pass }}\left(\mathrm{A} \mathrm{cm}^{-2}\right)$ \\
\hline CP Ti & $-0.475 \pm 0.017$ & $(10.1 \pm 1.1) \times 10^{-6}$ \\
015CA & $0.091 \pm 0.022$ & $(2.8 \pm 1.0) \times 10^{-8}$ \\
035CA & $-0.017 \pm 0.032$ & $(3.8 \pm 0.5) \times 10^{-8}$ \\
\hline
\end{tabular}

dissolution of the anodic film. Banakh et al. [35] evaluated the response of anodic oxide layers containing $\mathrm{Ca}$ and $\mathrm{P}$ by immersion in a simulated body fluid and reported that $\mathrm{Ca}$ and $\mathrm{P}$ content in the anodic layers decreased after 14 days of immersion. Moreover, Ca dissolution occurs at higher rates than P. However, during the immersion period, the anodic treated samples presented more positive values than untreated $\mathrm{Ti}$ indicating a lower tendency to corrosion.

\subsubsection{Electrochemical Impedance Spectroscopy}

Fig. 8 shows the electrochemical impedance spectra for $\mathrm{Ti}$ in the form of Nyquist and Bode diagrams for different times of immersion. At high frequencies $\left(10^{2} \mathrm{~Hz}\right.$ to $\left.10^{5} \mathrm{~Hz}\right)$, the Bode diagram shows constant values of $|\mathrm{Z}|$ where the phase angle was near $0^{\circ}$ which corresponds to the response of the electrolyte resistance. At low and middle frequencies, the phase angle presented values approaching $90^{\circ}$ which is a typical capacitive behaviour of a compact oxide film. The protective character of this film seemed to be enhanced with increased immersion time, as already concluded from the OCP evolution.

Fig. 9 presents the equivalent electrical circuit for the native oxide film formed on the surface of the CP Ti samples used in the fitting of the experimental data, containing: $R_{s}$ - electrolyte resistance, $R_{b f(N)}$ - native barrier oxide film resistance and $Q_{b f(N)}$ constant phase element (CPE), accounting for the non-ideal capacitance of the native barrier oxide film.

$\mathrm{Q}_{\mathrm{bf}(\mathrm{N})}$ values were converted to $\mathrm{C}_{\mathrm{bf}(\mathrm{N})}$ (capacitance of the native oxide film) by using Eq. (2), derived from Brug's equation [58].

$C_{b f(N)}=\left[Q_{b f(N)} R_{s}^{(1-n)}\right]^{\frac{1}{n}}$

The equivalent circuit parameters obtained from EIS data for the untreated Ti at different immersion times are shown in Table 3. As can be seen from the fitting results, the values of $\mathrm{R}_{\mathrm{bf}(\mathrm{N})}$ increase and those of $\mathrm{C}_{\mathrm{bf}(\mathrm{N})}$ decrease with the increased immersion time, indicating a higher protection of the passive oxide film formed on the surface at longer immersion time.

Fig. 10 presents the electrochemical impedance spectra in the form of Nyquist and Bode diagrams, obtained at different immersion times for the anodic treated samples. The 015CA group presented two time constants: one corresponding to the high frequencies being shifted to higher frequencies values as time elapses. The 035CA presented a similar behaviour to the 015CA at the beginning of immersion but the resistance corresponding to the high frequencies time constant was considerably lower than that of the 015CA. Both groups presented a phase angle near $-80^{\circ}$, for the lowest frequencies range $\left(10^{-2}-10^{-1} \mathrm{~Hz}\right)$ during all the immersion period.

Different circuits for fitting EIS spectra on MAO treated Ti surfaces were found in the literature. Among other authors, Shokouhfar et al. [49] and Venkateswarlu et al. [33,50] used EEC consisting of two time constants, one at high frequency $\left(\mathrm{CPE}_{\mathrm{o}}\right.$ with a resistance $R_{o}$ in parallel), characteristic of the outer porous layer, and the second corresponding to low frequencies and being characteristic of the inner barrier layer of the film, consisting in a $C P E_{b}$ with a resistance $R_{b}$ in parallel. Both authors present $R_{o}$ as the "outer porous layer resistance", although obtaining quite low values for this parameter, as commented by both authors. In fact, $\mathrm{R}_{\mathrm{o}}$ should not be assigned to the resistance of the outer oxides, but to the additional solution resistance in their pores. Both the layout of the EEC, where $R_{o}$ is in series with the contribution of the inner barrier layer, and the low $R_{o}$ values point out to this interpretation. Additionally, Pan et al. [51] have introduced this interpretation in their publications, mentioning that $\mathrm{R}_{\mathrm{o}}$ (referred as $\mathrm{R}_{\mathrm{p}}$ in their work) could be either the outer layer resistance or the electrolyte resistance inside pores.

On the other hand, Fazel et al. [42] used a similar circuit for MAO treated Ti surfaces but the authors added a constant phase element $\left(Q_{d}\right)$ in series with $R_{b}$ which was assigned to diffusion of ions through the oxide layer. This interpretation is questionable, as the $n$ value obtained by these authors for that constant phase element is 0.845 , far from the typical values expected for diffusioncontrolled processes (ca. 0.5) and closer to those of a capacitance of a rough oxide. Thus, even if it fits the experimental data, the proposed EEC lacks physical meaning, which is a major requirement for acceptance of an EEC.

Several studies [56,59-61] used EEC containing $R_{s}$ (electrolyte's solution), an outer porous oxide layer $\left(\mathrm{CPE}_{\mathrm{p}}\right.$ and $\mathrm{R}_{\mathrm{p}}$ ), an inner dense barrier oxide layer $\left(\mathrm{CPE}_{\mathrm{b}}\right.$ and $\mathrm{R}_{\mathrm{b}}$ ) and a Warburg diffusion element 


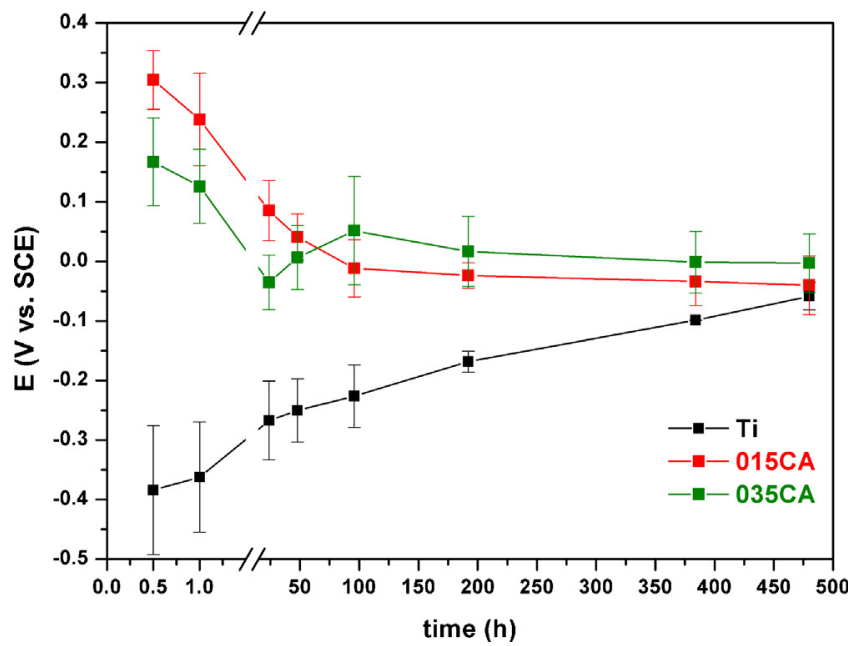

Fig. 7. Open circuit potential evolution with immersion time of the different group of samples in $\mathrm{NaCl}(8 \mathrm{~g} / \mathrm{l})$.

to account for the mass-transfer process inside the irregular shaped pores in the oxide. However, diffusion control is not very much expected in these materials, as the rate of any faradaic reaction (especially metal oxidation) is expected to be very low. On the other hand, Quintero et al. [40] proposed a different equivalent circuit for similar anodic treated surfaces, in a 3 time constant ladder arrangement, consisting of the contributions of the outer layer, inner layer and metal/electrolyte interface at the bottom of nanometric pores of a not completely homogeneous inner layer that would allow contact between the $\mathrm{Ti}$ substrate and the electrolyte. However, the fittings presented by these authors are very poor, with $\chi^{2}$ values close to $10^{-2}$, which may question the validity of their circuit.

In summary, all the circuits presented in the literature, both relative to standard anodising or MAO, assumed a two-layered oxide film, with an inner barrier layer and an outer porous layer, although some of them may include other elements, such as Warburg or CPE's, normally assigned to diffusion control. However, by choosing from these circuits the ones that have a clear physical meaning, none of them was able to provide acceptable fitting to the impedance spectra of the present anodic treated samples. In fact, based on the structure of the anodic film, as revealed from the cross

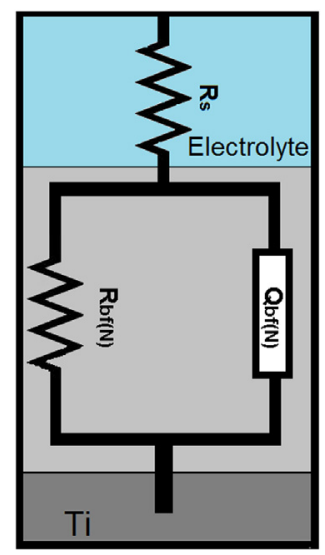

\section{Rs - electrolyte resistance}

Rbf(N) - native barrier oxide film resistance

Qbf(N) - CPE of the native barrier oxide film

Fig. 9. Equivalent circuit proposed for the fitting of EIS spectra for the untreated $\mathrm{CP}$ Ti (grade 2) samples.

sections of the anodic oxide films prepared by SEM-FIB and characterized by FEG-SEM/EDS (Fig. 3), and on the EIS diagrams (Fig. 10), a triplex structure is considered, with a thin and compact oxide film formed at the metal/oxide interface (barrier film) followed by two porous layers, namely an inner porous layer presenting small pores and an outer porous layer, formed at the surface, that consisted in larger pores but not reaching the barrier film. Therefore, a new equivalent circuit is proposed (Fig. 11), where the barrier film is associated to a resistor $R_{b f(A T)}$ and a

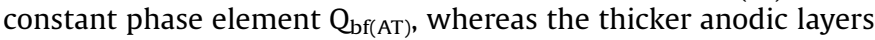
corresponding to the intact porous wall and to the porous wall under the outer pores are represented by $Q_{\text {wall }}$ and $Q_{1 / 2 \text { wall }}$ respectively. In these last cases, no resistor is considered in parallel with the CPE's as, due to the thickness of the films, the respective value would be extremely high. Three resistors were also added, corresponding to the overall electrolyte resistance, $R_{s}$ and to the additional resistances of the solution inside the inner pores and outer pores $\left(\mathrm{R}_{\mathrm{s} \text {-ip }}, \mathrm{R}_{\mathrm{s} \text {-op }}\right)$.

The impedance spectra for the anodised samples were fitted to this equivalent circuit using ZView software (version 2.9) and the quality of the fitting was evaluated through their chi-square $\left(\chi^{2}\right)$ values.

The impedance of CPE is defined as $Z_{C P E}=\left[Y_{0}(j w)^{n}\right]^{-1}$, where $Y_{0}$ is the CPE admittance, $\omega$ is the angular frequency, $\mathrm{n}$ the
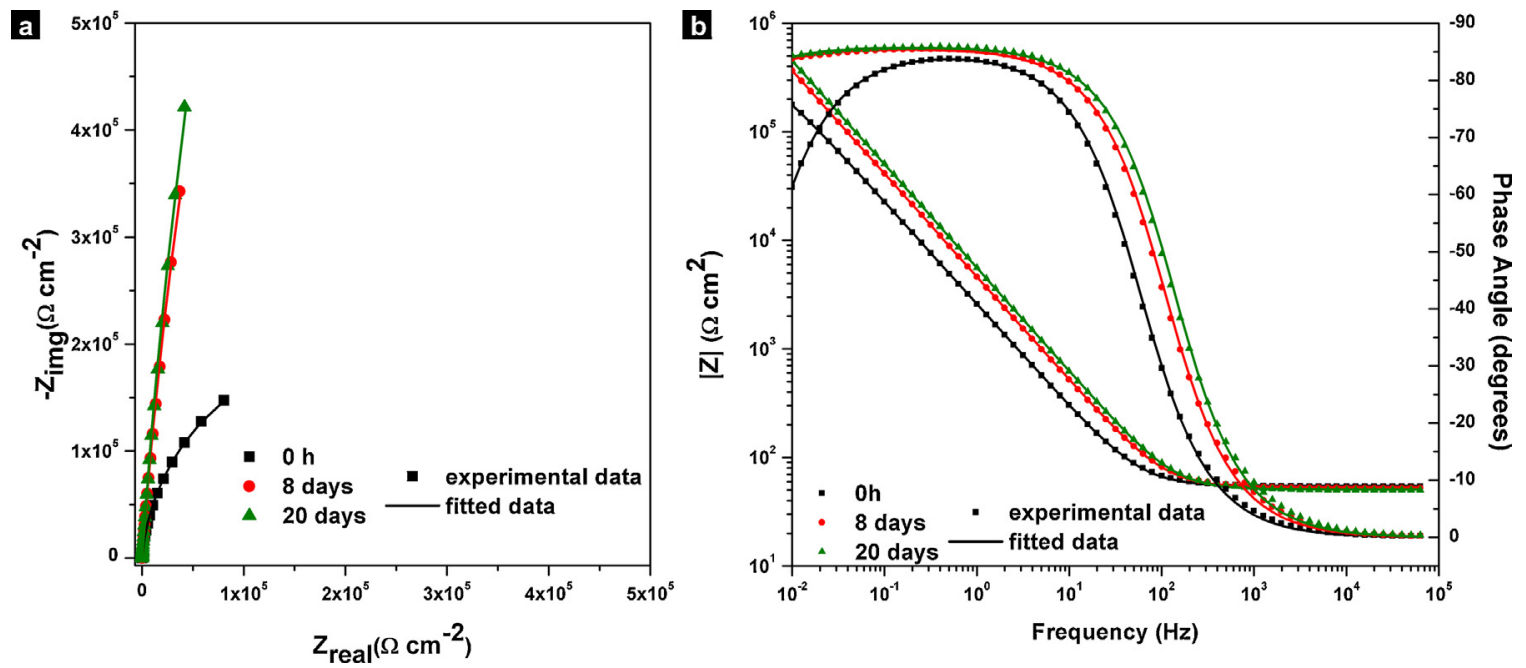

Fig. 8. Nyquist and Bode diagrams recorded on the untreated $\mathrm{CP}$ Ti (Grade 2 ) immersed in $\mathrm{NaCl}(8 \mathrm{~g} / \mathrm{l})$ for $0 \mathrm{~h}, 8 \mathrm{days}$ and 20 days of immersion. 
Table 3

Equivalent circuit parameters obtained from EIS data for the untreated Ti at different immersion times.

\begin{tabular}{|c|c|c|c|c|c|c|c|c|}
\hline & Oh & $1 \mathrm{~h}$ & 24h (1day) & 48h (2days) & 96h (4days) & 192h (8days) & 384h (16days) & 480h (20days) \\
\hline$R_{s}\left(\Omega \mathrm{cm}^{2}\right)$ & $47.9 \pm 5.1$ & $47.6 \pm 5.1$ & $47.7 \pm 4.2$ & $48.5 \pm 5.1$ & $45.8 \pm 3.8$ & $46.0 \pm 5.8$ & $46.0 \pm 5.8$ & $44.3 \pm 5.8$ \\
\hline$R_{b f(N)}\left(M \Omega \mathrm{cm}^{2}\right)$ & $0.37 \pm 0.06$ & $0.53 \pm 0.02$ & $2.54 \pm 1.39$ & $5.33 \pm 0.01$ & $6.51 \pm 1.01$ & $6.60 \pm 0.89$ & $8.15 \pm 1.30$ & $11.30 \pm 3.46$ \\
\hline$C_{b f(N)}\left(\mu F\right.$ cm $\left.^{-2}\right)$ & $48.6 \pm 4.1$ & $47.7 \pm 3.7$ & $44.1 \pm 2.0$ & $39.0 \pm 0.9$ & $35.6 \pm 3.5$ & $35.0 \pm 1.6$ & $33.6 \pm 0.4$ & $28.2 \pm 5.7$ \\
\hline n & $0.92 \pm 0.02$ & $0.93 \pm 0.02$ & $0.93 \pm 0.01$ & $0.93 \pm 0.02$ & $0.93 \pm 0.02$ & $0.94 \pm 0.02$ & $0.94 \pm 0.01$ & $0.95 \pm 0.02$ \\
\hline$x^{2}$ & $<1.35 \times 10^{-3}$ & $<1.15 \times 10^{-3}$ & $<1.58 \times 10^{-3}$ & $<1.87 \times 10^{-3}$ & $<1.53 \times 10^{-3}$ & $<1.16 \times 10^{-3}$ & $<0.87 \times 10^{-3}$ & $<1.13 \times 10^{-3}$ \\
\hline
\end{tabular}
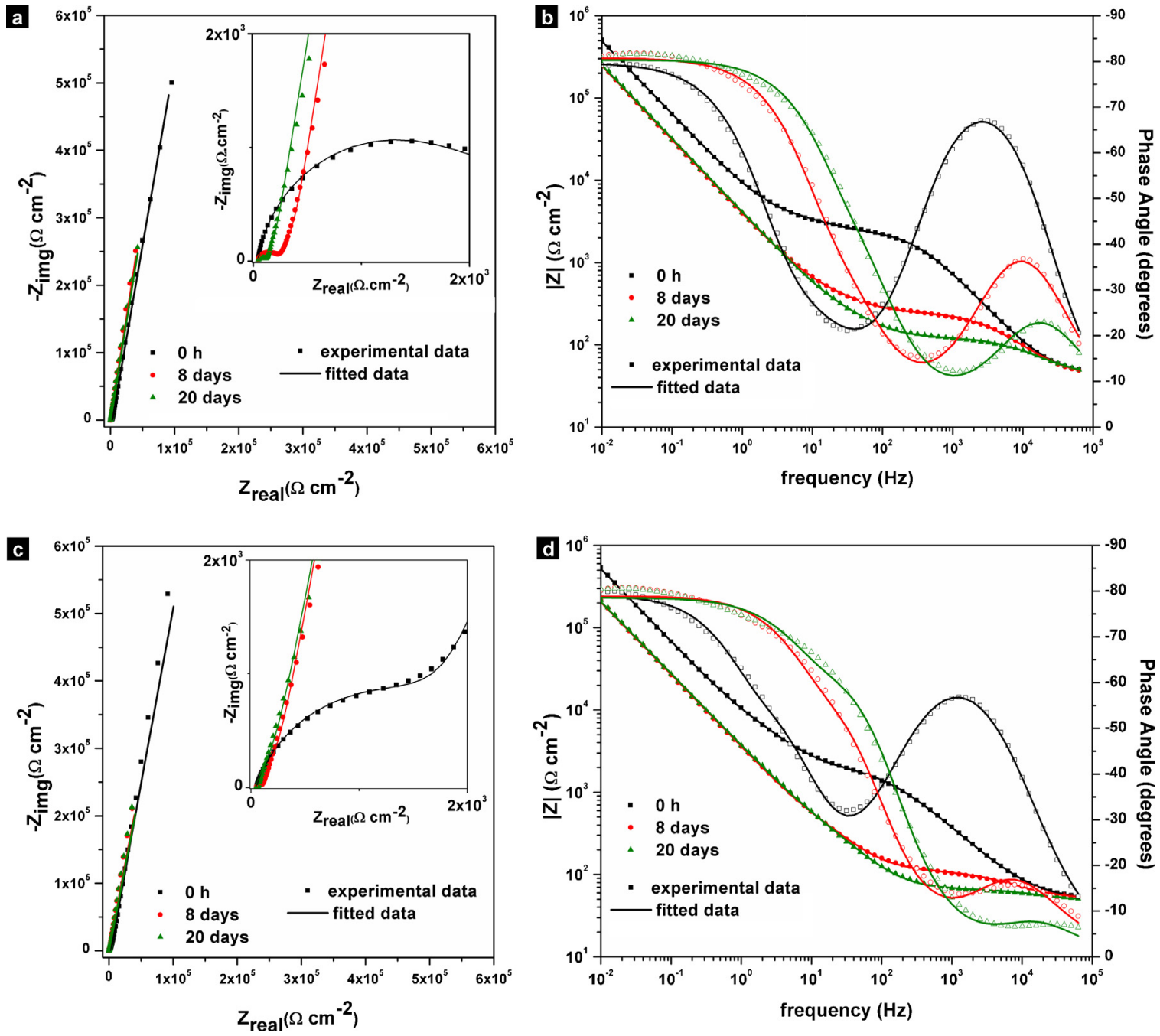

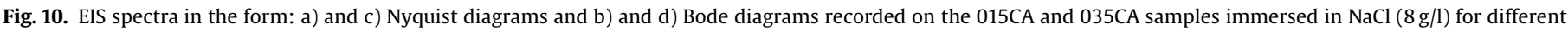
immersion times.

exponential factor $(-1 \leq n \leq 1)$ and $j=\sqrt{-1}$ is the imaginary number. When $n=1, n=0$ and $n=-1$, the CPE responses correspond to those of a capacitor, a resistor or an inductor, respectively. When $n \approx 1$, a non-ideal capacitor may be described by this element, the $n$ value being influenced by the roughness of the surface and its heterogeneity. As can be observed in Fig. 2, all groups of samples presented rough surfaces, resulting in a range of $n$ values between 0.90 and 0.93 .

Fig. 12 shows the Bode diagrams of experimental data and the respective fitted curves, comparing the proposed model (Fig. 11b) and one of the models that has been used in the literature for titanium anodic films produced by MAO $[33,49,50]$ (Fig. 11a). These diagrams show differences in the quality of the simulation by using the two different models. The proposed model describes adequately the behaviour of the anodic film in contact with $\mathrm{NaCl}$, with chi-square values often below $1 \times 10^{-3}$, whereas the duplex model does not satisfactorily fit the behaviour of the anodic oxide films, with chi-square values around $1 \times 10^{-2}$.

The conversion of $\mathrm{Q}$ values into $\mathrm{C}$ (capacitance) is very important when experimental capacitance data are used to estimate the parameters as the thickness of anodized layers [62]. Thus, the capacitance values were calculated in the case of $C_{\text {wall }}$ (3) and $C_{1 / 2 \text { wall }}$ (4) using Eqs. ( 3 ) and (4) respectively that were extrapolated from Brug's equation [58]. On the other hand, the Eq. (5) was used to calculate $C_{b f(A T)}$, when a resistor exists in parallel with the CPE [58].

$C_{\text {wall }}=\left[Q_{\text {wall }} R_{s}^{(1-n)}\right]^{\frac{1}{n}}$ 


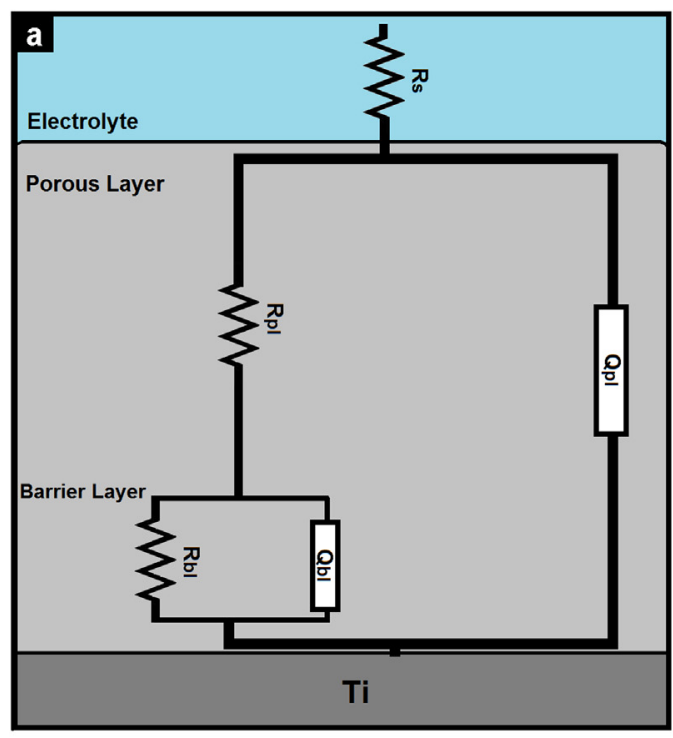

Rs - electrolyte resistance $\mathrm{Rpl}$ - porous layer resistance Qpl - CPE of the porous layer Rbl - barrier layer resistance $\mathrm{Qbl}$ - CPE of the barrier layer

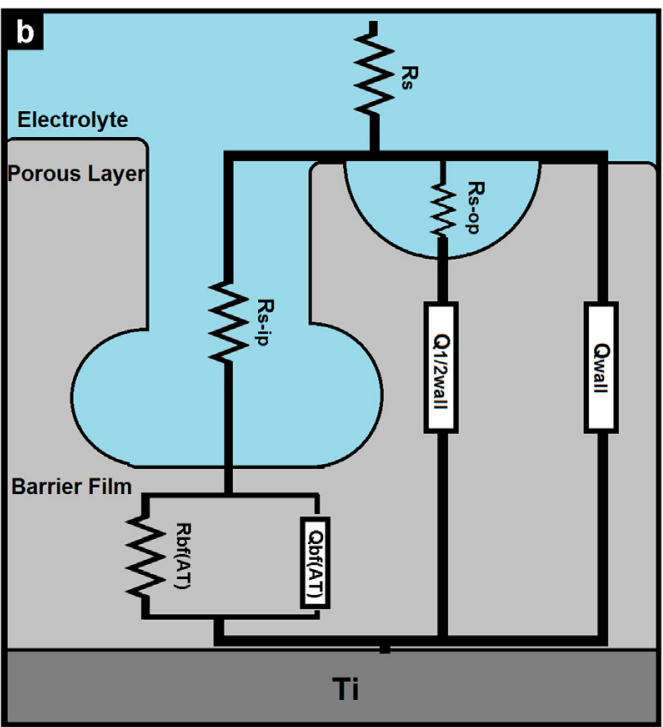

Rs - electrolyte resistance Rs-ip - inner pore's solution resistance Rs-op - outer pore's solution resiatnce Qwall - CPE of the wall pore Q1/2wall- CPE of the wall pore Rbf(AT) - barrier film resistance Qbf(AT) - CPE of the barrier film

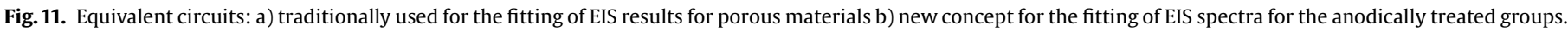
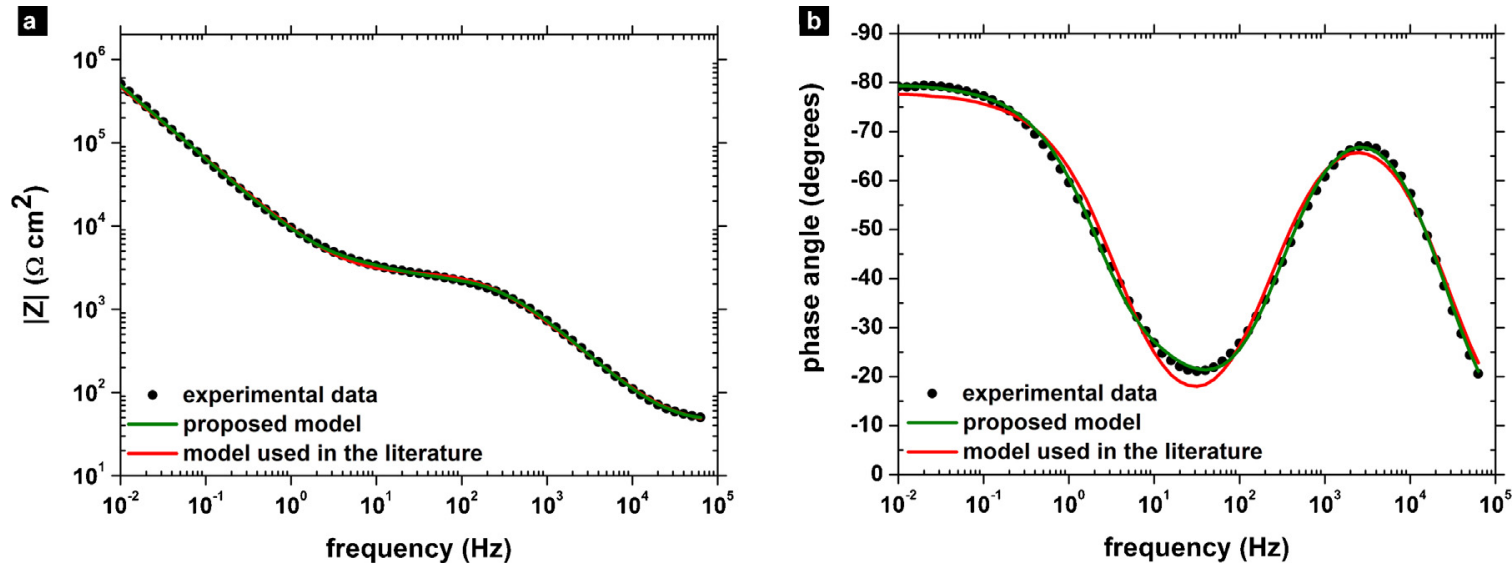

Fig. 12. Bode diagrams: a) impedance and b) phase angle of experimental data and fitted curves for $015 \mathrm{CA}$ samples immersed in $\mathrm{NaCl}(8 \mathrm{~g} / \mathrm{l})$ for $0 \mathrm{~h}$.

$C_{1 / 2 \text { wall }}=\left[Q_{1 / 2 \text { wall }}\left(R_{S}+R_{S-o p}\right)^{(1-n)}\right]^{\frac{1}{n}}$

$C_{b f(A T)}=\left[Q_{b f(A T)}\left(\frac{1}{R_{S}+R_{S-i p}}+\frac{1}{R_{b f(A T)}}\right)^{(n-1)}\right]^{\frac{1}{n}}$

Fig. 13 shows the variation of $\mathrm{C}_{1 / 2 \text { wall }}$ with immersion time for the anodically treated groups. The 035CA group presented higher values of capacitance than 015CA for all times of immersion. It is known that capacitance is proportional to the area. The 035CA group presented higher pore size and higher crack density $\left((7.1 \pm 1.6) \times 10^{3} \mathrm{cracks} / \mathrm{mm}^{2}\right)$ than $015 \mathrm{CA}\left((1.1 \pm 0.4) \times 10^{3}\right.$ cracks/ $\left.\mathrm{mm}^{2}\right)$, which can explain this behaviour. Besides, both groups presented an increase on $\mathrm{C}_{1 / 2 \text { wall }}$ values throughout the immersion time.

The variation of $C_{\text {wall }}$ with immersion time is presented in Fig. 14. The 035CA group presented always higher $C_{\text {wall }}$ values, increasing up to $24 \mathrm{~h}$ of immersion and then remaining almost constant till two days of immersion, followed by an increase till the end of immersion, while the values of $C_{\text {wall }}$ for 015CA are almost constant during the immersion period. In fact, during immersion, the solution can penetrate or attack the oxide film which may lead to pores blocking that may explain the decrease of $C_{\text {wall }}$ values. The 


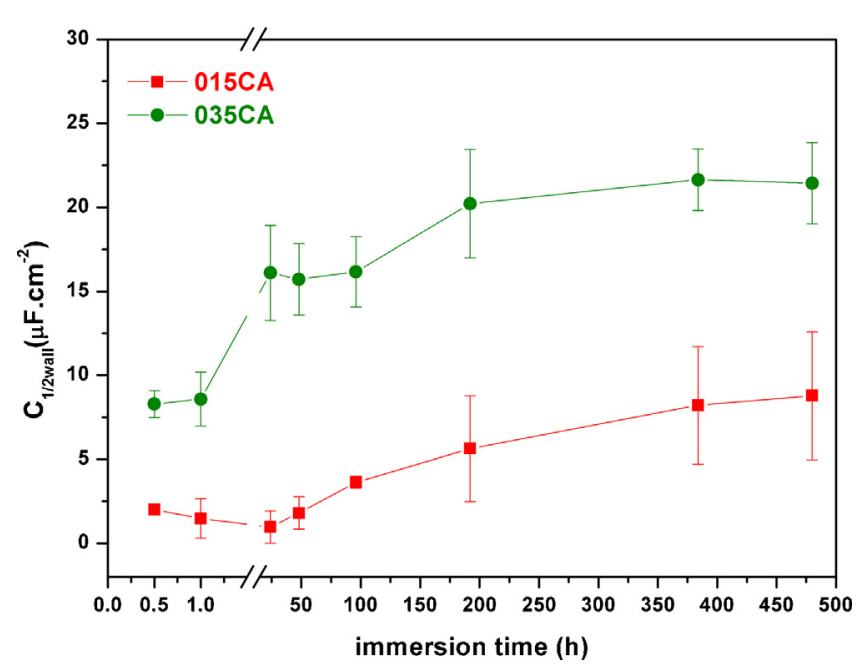

Fig. 13. Variation of $C_{1 / 2 \text { wall }}$ as function of immersion time.

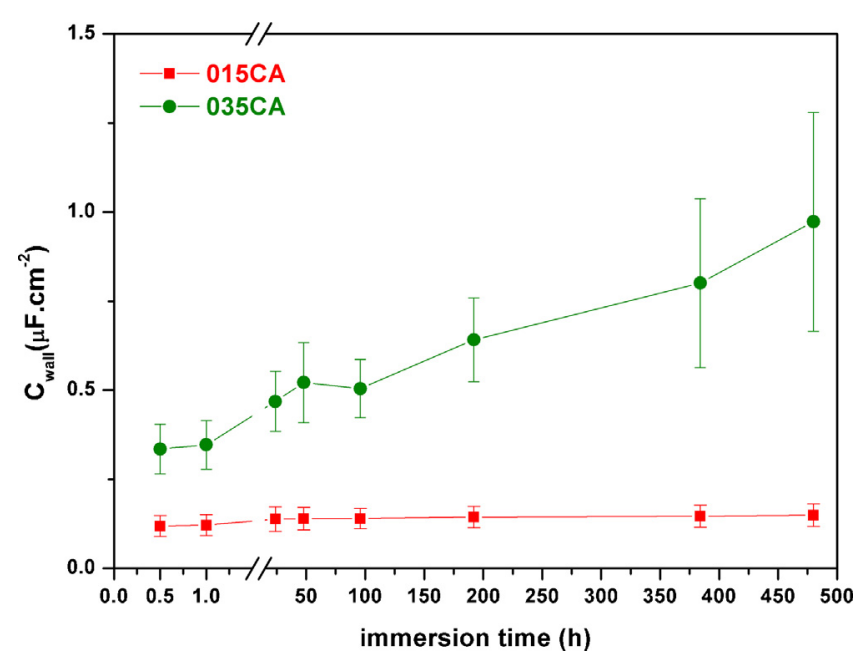

Fig. 14. Variation of $C_{\text {wall }}$ as function of immersion time.

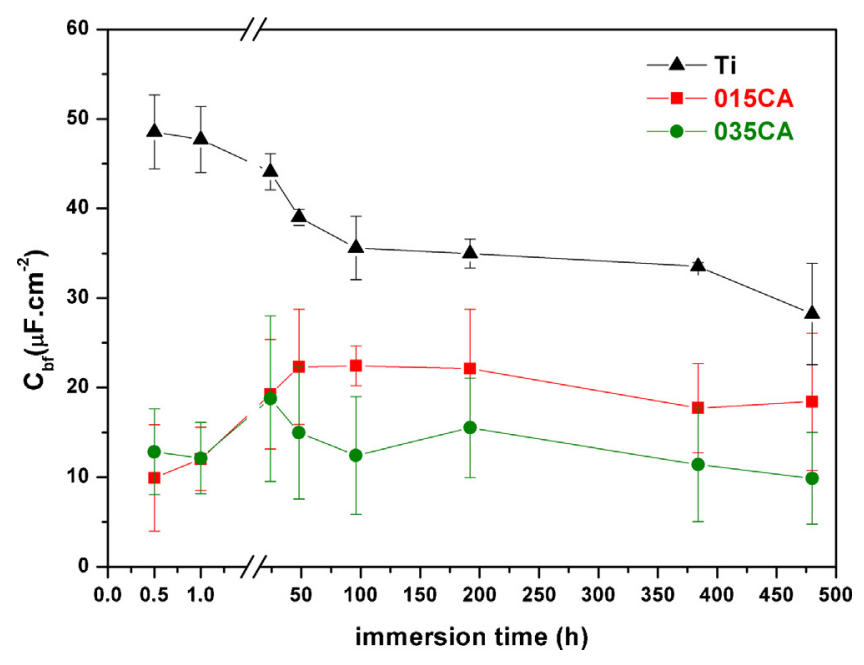

Fig. 15. Variation of $C_{b f}$ as function of immersion time.

electrolyte penetration through the pores on the 035CA group is facilitated, as this group presented bigger pores and higher number of cracks.
The barrier film behaviour is shown in Fig. 15. The barrier film of the anodic treated samples $\left(\mathrm{C}_{\mathrm{bf}(\mathrm{AT})}\right)$ was compared with the Ti native oxide film $\left(\mathrm{C}_{\mathrm{bf}(\mathrm{N})}\right)$ formed on its surface. Taking in account the standard deviation for the anodic treated group, it was possible to observe that the $C_{b f}$ values did not change significantly during the immersion time. However a decrease with time was observed for the untreated Ti that may be due to the contact with $\mathrm{H}_{2} \mathrm{O}$ leading to the hydration of the oxide film. If the growth rate of the oxide film is large enough, it can remain in hydrated form [63].

The values of $C_{\text {wall }}$ are considered representative of the capacitance of the intact porous wall, and may be affected both by variation of the exposed area of this layer and by variation of its thickness. It was concluded from Fig. 13 that the pore size increases with the immersion time, thus a slight decrease in the exposed area of intact wall is expected. However, taking into account that this area is quite large when compared to the pore area, its variation should not be very important.

On the other hand, according to the Eq. (6) the capacitance values depend on the thickness:

$C=\frac{\varepsilon \varepsilon_{0} A}{d}$

$d=\frac{\varepsilon \varepsilon_{0} A}{C}$

where, $\varepsilon$ is the dielectric constant of the oxide film, $\varepsilon_{0}$ is the vacuum permittivity, $A$ is the area and $d$ is the thickness. Considering $\varepsilon_{0}=8.854 \times 10^{-14} \mathrm{Fcm}^{-1}$ and $\varepsilon=100$ (typical dielectric constant for $\left.\mathrm{TiO}_{2}[64,65]\right)$, it may possible to estimate the film (wall) thickness at the beginning of the immersion and at the last immersion time. Thus, a decrease in the thickness of the overall film, resulting from its dissolution, would lead to an increase of the capacitance, as it occurs for 035CA group. In the case of the 015CA group, the effect of decreasing area may affect this behaviour, as it is observed from Figs. 13 and 14 that the enlargement of the pore size was much bigger in this type of specimens.

To get a better understanding of the electrochemical behaviour of the anodic oxide films under long-time immersion in physiological solution, the characterization of the anodic films cross-section should be done, as well potentiodynamic tests after different immersion times should be performed.

\section{Conclusions}

The effect of the calcium acetate concentration in the electrolyte used to anodize CP Ti on the composition, structure, and corrosion behaviour of the anodic layers was investigated. The outcomes of this work are the following:

- a new equivalent electrochemical circuit is proposed to fit the EIS spectra of anodic films produced by MAO. The equivalent circuit was established in accordance with the complex structure of the films and overcomes the limitations of already existing circuits proposed for this kind of materials. The proposed circuit has a clear physical meaning, allows for a good fitting of the experimental data and explains the changes in the EIS spectra relating them with the different characteristics of the anodic oxides.

- the corrosion resistance was improved by the surface treatment, with both concentrations of calcium acetate, when compared with untreated titanium. Nevertheless, higher concentrations of calcium acetate results in a detrimental effect on the corrosion resistance of the material, essentially due to the contribution of the cracks present in the outermost porous layer of the anodic film. The obtained knowledge is useful for the development of 
new strategies for the processing of MAO films in calcium-rich electrolytes with less amount of superficial cracks.

\section{Acknowledgments}

This work is supported by FCT with the reference project UID/ EEA/04436/2013, by FEDER funds through the COMPETE 2020 Programa Operacional Competitividade e Internacionalização (POCI) with the reference project POCI-01-0145-FEDER-006941. Part of this work was done within the Scientific Community on Surface Modification of Materials funded by FWO-Flanders (grant number WO.039.14N), and within the scope of the EU-funded COST MP1407 "E-MINDS. CQE is financed by FCT under contract UID/ QUI/00100/2013.

\section{References}

[1] M. Niinomi, Recent Metallic Materials for Biomedical Applications, Metall. Mater. Trans. A. 33 A (2002) 477-486.

[2] M. Niinomi, Mechanical biocompatibilities of titanium alloys for biomedical applications, J. Mech. Behav. Biomed. Mater. I (2008) 30-42.

[3] H.J. Rack, J.I. Qazi, Titanium alloys for biomedical applications, Mater. Sci. Eng. C. 26 (2006) 1269-1277.

[4] S.S. Dheda, Y. Kyung, C. Melnyk, W. Liu, F.A. Mohamed, Corrosion and in vitro biocompatibility properties of cryomilled-spark plasma sintered commercially pure titanium, J. Mater. Scinece Mater. Med. 24 (2013) 12391249.

[5] Y. Ni, Z. Liu, W. Gao, S. Qu, J. Weng, B. Feng, Characterization of self-assembled decyl bis phosphonate-Collagen layers on titanium by QCM-D and osteoblastcompatibility, Appl. Surf. Sci. 257 (2011) 9287-9292.

[6] Y.J. Chen, B. Feng, Y.P. Zhu, J. Weng, J.X. Wang, X. Lu, Fabrication of porous titanium implants with biomechanical compatibility, Mater. Lett. 63 (2009) 2659-2661.

[7] G. He, L. Xie, G.-F. Yin, X.-M. Liao, Y.-W. Zou, Z.-B. Huang, et al., Synthesis and mechanism of (101)-preferred orientation rutile titania via anodic spark oxidation, Surf. Coat. Technol. 228 (2013) 201-208.

[8] H. Song, M. Kim, G. Jung, M. Vang, Y. Park, The effects of spark anodizing treatment of pure titanium metals and titanium alloys on corrosion characteristics, Surf. Coat. Technol. 201 (2007) 8738-8745.

[9] L. Le Guéhennec, A. Soueidan, P. Layrolle, Y. Amouriq, Surface treatments of titanium dental implants for rapid osseointegration, Dent. Mater. 3 (2007) 844-854.

[10] H. Ishizawa, M. Fujino, M. Ogino, Histomorphometric evaluation of the thin hydroxyapatite layer formed through anodization followed by hydrothermal treatment, J. Biomed. Mater. Res. 35 (1997) 199-206.

[11] Y. Yang, J.L. Ong, J. Tian, In vivo evaluation of modified titanium implant surfaces produced using a hybrid plasma spraying processing, Mater. Sci. Eng. C. 20 (2002) $117-124$.

[12] S. Vercaigne, J.G. Wolke, I. Naert, J.A. Jansen, The effect of titanium plasmasprayed implants on trabecular bone healing in the goat, Biomaterials. 19 (1998) 1093-1099.

[13] T. Hanawa, In vivo metallic biomaterials and surface modification, Mater. Sci. Eng. A. 267 (1999) 260-266.

[14] T. Hanawa, H. Ukai, K. Murakami, K. Asaoka, Structure of Surface-Modified Layers of Calcium-Ion-Implanted Ti-6Al-4 V and Ti-56Ni, Mater. Trans. 36 (1995) 438-444.

[15] M. Pham, M. Maitz, W. Matz, H. Reuther, E. Richter, G. Steiner, Promoted hydroxyapatite nucleation on titanium ion-implanted with sodium, Thin Solid Films. 379 (2000) 50-56.

[16] A. Montenero, G. Gnappi, F. Ferrari, M. Cesari, E. Salvioli, L. Mattogno, et al., Solgel derived porous hydroxyapatite coatings, J. Mater. Sci. 35 (2000) 2791-2797.

[17] H.-W. Kim, Y.-H. Koh, L.-H. Li, S. Lee, H.-E. Kim, Hydroxyapatite coating on titanium substrate with titania buffer layer processed by sol-gel method, Biomaterials. 25 (2004) 2533-2538.

[18] Y. Wang, J. Wang, J. Zhang, Z. Zhang, Effects of spark discharge on the anodic coatings on magnesium alloy, Mater. Lett. 60 (2006) 474-478.

[19] H. Ishizawa, M. Ogino, Characterization of thin hydroxyapatite layers formed on anodic titanium oxide films containing $\mathrm{Ca}$ and $\mathrm{P}$ by hydrothermal treatment, J. Biomed. Mater. Res. 29 (1995) 1071-1079.

[20] H. Ishizawa, M. Fujino, M. Ogino, Mechanical and histological investigation of hydrothermally treated and untreated anodic titanium oxide films containing Ca and P, J. Biomed. Mater. Res. 29 (1995) 1459-1468.

[21] H. Ishizawa, M. Ogino, Formation and characterization of anodic titanium oxide films containing Ca and P, J. Biomed. Mater. Res. 29 (1995) 65-72.

[22] I.S. Park, T.S. Bae, K.W. Seol, Surface Characteristics of Anodized and Hydrothermally Treated Titanium with an Increasing Concentration of Calcium Ion, Met. Mater. Int 12 (2006) 399-406.

[23] E.M. Szesz, B.L. Pereira, N.K. Kuromoto, C.E.B. Marino, G.B. de Souza, P. Soares, Electrochemical and morphological analyses on the titanium surface modified by shot blasting and anodic oxidation processes, Thin Solid Films. 528 (2013) 163-166.

[24] M.E.P. Souza, M. Ballester, C.M.A. Freire, EIS characterisation of Ti anodic oxide porous films formed using modulated potential, Surf. Coat. Technol. 201 (2007) 7775-7780.

[25] K. Kim, T. Kwon, S. Kim, I. Kang, S. Kim, Y. Yang, et al., Preparation and characterization of anodized titanium surfaces and their effect on osteoblast responses, J. Oral Implantol. 32 (2006) 8-13.

[26] F. Deng, W. Zhang, P. Zhang, C. Liu, J. Ling, Improvement in the morphology of micro-arc oxidised titanium surfaces: A new process to increase osteoblast response, Mater. Sci. Eng. C. 30 (2010) 141-147.

[27] S. Yu, X. Yang, L. Yang, Y. Liu, Y. Yu, Novel Technique for Preparing Ca- and PContaining Ceramic Coating on Ti-6Al-4 V by Micro-Arc Oxidation, J. Biomed. Mater. Res. Part B Appl. Biomater 83 (2007) 623-627.

[28] I.S. Park, T.G. Woo, W.Y. Jeon, H.H. Park, M.H. Lee, T.S. Bae, et al., Surface characteristics of titanium anodized in the four different types of electrolyte, Electrochim. Acta. 53 (2007) 863-870.

[29] H. Ishizawa, M. Fujino, M. Ogino, Mechanical and histological investigation of hydrothermally treated and untreated anodic titanium oxide films containing Ca and P, J. Biomed. Mater. Res. 29 (1995) 1459-1468.

[30] H. Ishizawa, M. Ogino, Hydrothermal precipitation of hydroxyapatite on anodic titanium oxide films containing Ca and P, J. Mater. Sci. 34 (1999) 5893 5898.

[31] S.A. Fadl-allah, Q. Mohsen, Characterization of native and anodic oxide films formed on commercial pure titanium using electrochemical properties and morphology techniques, Appl. Surf. Sci. 256 (2010) 5849-5855.

[32] L.-H. Li, Y.-M. Kong, H.-W. Kim, Y.-W. Kim, Improved biological performance of Ti implants due to surface modification by micro-arc oxidation, Biomaterials. 25 (2004) 2867-2875.

[33] K. Venkateswarlu, N. Rameshbabu, D. Sreekanth, A.C. Bose, V. Muthupandi, S. Subramanian, Fabrication and characterization of micro-arc oxidized fluoride containing titania films on Cp Ti, Ceram. Int. 39 (2013) 801-8012.

[34] W.F. Cui, L. Jin, L. Zhou, Surface characteristics and electrochemical corrosion behavior of a pre-anodized microarc oxidation coating on titanium alloy, Mater. Sci. Eng. C. 33 (2013) 3775-3779.

[35] O. Banakh, T. Journot, P.-A. Gay, J. Matthey, C. Csefalvay, O. Kalinichenko, et al., Synthesis by anodic-spark deposition of Ca- and P-containing films on pure titanium and their biological response, Appl. Surf. Sci. 378 (2016) 207-215.

[36] P.-C. Chang, B.-Y. Liu, C.-M. Liu, H.-H. Chou, M-H. Ho, H.-C. Liu, et al., Purified titanium oxide with novel morphologies upon spark anodization of Ti alloys in mixed H2S04/H3PO4 electrolytes, J. Biomed. Mater. Res. A. 80 (2007) 283-296.

[37] S. Abbasi, F. Golestani-Fard, S.M.M. Mirhosseini, A. Ziaee, M. Mehrjoo, Effect of electrolyte concentration on microstructure and properties of micro arc oxidized hydroxyapatite/titania nanostructured composite, Mater. Sci. Eng. C. 33 (2013) 2555-2561.

[38] I. Han, J.H. Choi, B.H. Zhao, H.K. Baik, I.-S. Lee, Changes in anodized titanium surface morphology by virtue of different unipolar DC pulse waveform, Surf. Coatings Technol. 201 (2007) 5533-5536.

[39] N.K. Kuromoto, R.A. Simão, G.A. Soares, Titanium oxide films produced on commercially pure titanium by anodic oxidation with different voltages, Mater. Charact. 58 (2007) 114-121.

[40] D. Quintero, O. Galvis, J.A. Calderón, J.G. Castaño, F. Echeverría, Effect of electrochemical parameters on the formation of anodic films on commercially pure titanium by plasma electrolytic oxidation, Surf. Coatings Technol. 258 (2014) 1223-1231.

[41] D. Veys-Renaux, Z.A. El Haj, E. Rocca, Corrosion resistance in artificial saliva of titanium anodized by plasma electrolytic oxidation in Na3PO4, Surf. Coatings Technol. 285 (2016) 214-219.

[42] M. Fazel, H.R. Salimijazi, M.A. Golozar, M.R. Garsivaz jazi, A comparison of corrosion, tribocorrosion and electrochemical impedance properties of pure Ti and Ti6Al4 V alloy treated by micro-arc oxidation process, Appl. Surf. Sci. 324 (2015) 751-756.

[43] S.A. Alves, R. Bayón, V.S. de Viteri, M.P. Garcia, A. Igartua, M.H. Fernandes, et al., Tribocorrosion Behavior of Calcium- and Phosphorous-Enriched Titanium Oxide Films and Study of Osteoblast Interactions for Dental Implants, J. BioTribo-Corrosion 1 (2015) 23.

[44] S.A. Alves, R. Bayón, A. Igartua, V. Saénz de Viteri, L.A. Rocha, Tribocorrosion behaviour of anodic titanium oxide films produced by plasma electrolytic oxidation for dental implants, Lubr. Sci. 26 (2014) 500-513.

[45] A.C. Alves, F. Oliveira, F. Wenger, P. Ponthiaux, J.-P. Celis, L.A. Rocha, Tribocorrosion behaviour of anodic treated titanium surfaces intended for dental implants, J. Phys. D Appl. Phys. 46 (2013) 404001-404009.

[46] H.P. Felgueiras, L. Castanheira, S. Changotade, F. Poirier, S. Oughlis, M. Henriques, et al., Biotribocorrosion (tribo-electrochemical) characterization of anodized titanium biomaterial containing calcium and phosphorus before and after osteoblastic cell culture, J. Biomed. Mater. Res. Part B Appl. Biomater. 103 (2015) 661-669.

[47] A.R. Ribeiro, F. Oliveira, L.C. Boldrini, P.E. Leite, P. Falagan-Lotsch, A.B.R. Linhares, et al., Micro-arc oxidation as a tool to develop multifunctional calcium-rich surfaces for dental implant applications, Mater. Sci. Eng. C. 54 (2015) 196-206.

[48] F.G. Oliveira, A.R. Ribeiro, G. Perez, B.S. Archanjo, C.P. Gouvea, J.R. Araújo, et al., Understanding Growth Mechanisms and Tribocorrosion Behaviour of Porous TiO2 Anodic Films Containing Calcium, Phosphorous and Magnesium, Appl. Surf. Sci. 341 (2015) 1-12. 
[49] M. Shokouhfar, C. Dehghanian, A. Montenero, A. Baradaran, Preparation of ceramic coating on Ti substrate by plasma electrolytic oxidation in different electrolytes and evaluation of its corrosion resistance: Part II, Appl. Surf. Sci. 258 (2012) 2416-2423.

[50] K. Venkateswarlu, N. Rameshbabu, D. Sreekanth, A.C. Bose, V. Muthupandi, Role of electrolyte additives on in-vitro electrochemical behavior of micro arc oxidized titania films on Cp Ti, Appl. Surf. Sci. 258 (2012) 6853-6863.

[51] J. Pan, D. Thierry, C. Leygraf, Electrochemical impedance spectroscopy study of the passive oxide film on titanium for implant application, Electrochim. Acta. (1996) 1143-1153.

[52] D.C. Grahame, Mathematical Theory of the Faradaic Admittance (Pseudocapacity and Polarization Resistance), J. Electrochem. Soc 99 (1952) 370-385.

[53] S.-D. Wu, H. Zhang, X.-D. Dong, C.-Y. Ning, A.S.L. Fok, Y. Wang, Physicochemical properties and in vitro cytocompatibility of modified titanium surfaces prepared via micro-arc oxidation with different calcium concentrations, Appl. Surf. Sci. 329 (2015) 347-355.

[54] Y.-T. Sul, C.B. Johansson, Y. Jeong, T. Albrektsson, The electrochemical oxide growth behaviour on titanium in acid and alkaline electrolytes, Med. Eng. Phys. 23 (2001) 329-346.

[55] R.S. Williamson, J. Disegi, J.A. Griggs, M.D. Roach, Nanopore formation on the surface oxide of commercially pure titanium grade 4 using a pulsed anodization method in sulfuric acid, J. Mater. Sci. Mater. Med. 24 (2013) 2327 2335.

[56] M.D. Roach, R.S. Williamson, I.P. Blakely, L.M. Didier, Tuning anatase and rutile phase ratios and nanoscale surface features by anodization processing onto titanium substrate surfaces, Mater. Sci. Eng. C. 58 (2016) 213-223.
[57] K. Elagli, M. Traisnel, H.F. Hildebrand, Electrochemical behaviour of titanium and dental alloys in artificial saliva, Electrochim. Acta. 38 (1993) 1769-1774.

[58] M.E. Orazem, B. Tribollet, Electrochemical Impedance Spectroscopy, Jonh Wiley \& Sons, Inc. Publications, New Jersey, 2008.

[59] E. Matykina, R. Arrabal, M. Mohedano, A. Pardo, M.C. Merino, E. Rivero, Stability of plasma electrolytic oxidation coating on titanium in artificial saliva, J. Mater. Sci. Med. (2013) 37-51.

[60] M. Mohedano, E. Matykina, R. Arrabal, A. Pardo, M.C. Merino, Metal release from ceramic coatings for dental implants, Dent. Mater. 30 (2013) e28-e40.

[61] E. Matykina, R. Arrabal, B. Mingo, M. Mohedano, A. Pardo, M.C. Merino, In vitro corrosion performance of PEO coated Ti and Ti6Al4V used for dental and orthopaedic implants, Surf. Coat. Technol. 307 (2016) 1255-1264.

[62] C.H. Hsu, F. Mansfeld, Technical Note: Concerning the Conversion of the Constant Phase Element Parameter Yo into a Capacitance, Corrosion 57 (2001) 747-748.

[63] T. Ohtsuka, N. Nomura, The dependence of the optical property of Ti anodic oxide film on its growth rate by ellipsometry, Corros. Sci. 39 (1997) 1253-1263.

[64] J. Lundstrom, L. Rinehart, R. Pate, T. Smith, M. Krogh, W. Huebner, Measurement of the dielectric strength of titanium dioxide ceramics Pulsed Power, Conf. Dig. Tecnhical Pap. 12th IEEE Int (1999) 10-12.

[65] A. Wypych, I. Bobowska, M. Tracz, A. Opasinska, S. Kadlubowski, A. KrzywaniaKaliszewska, et al., Dielectric properties and characterisation of titanium dioxide obtained by different chemistry methods, J. Nanomater. 2014 (2014) $1-9$. 